\title{
Investigation of structure and properties of linear acetylenic carbon coatings for medical polymeric materials
}

\author{
Valentin Morozov ${ }^{1, *}$, Alexey Zhdanov ${ }^{1}$, and Leonid Belyaev ${ }^{1}$ \\ ${ }^{1}$ Department of Mechanical Engineering, Vladimir State University named after Alexander and Nikolay Stoletovs, Vladimir, Russia
}

\begin{abstract}
Results of researches of structure and properties of the nanostructured carbon coatings deposited on a polyurethane substrate are presented in article. Possibility of application of the scanning probe microscope methods and sclerometer method for quality control of the nanostructured carbon coatings is shown. The results of researches showing that the nanostructured carbon coatings deposited on polyurethane have high degree of adhesion to a substrate, reduce porosity of surface and increase its durability and wear resistance, increase elasticity and coefficient of restitution at deformation are given.
\end{abstract}

\section{Introduction}

In developing of biomedical materials one of the most important the problem is a biological compatibility which is caused by influence of the biological environment on a material and influence of a material on surrounding fabrics. Materials suitable for these purposes are the polymers steady against influence of biological environments, and also not undergoing metabolic destruction in an organism.

At the present time absolutely biocompatible polymeric material doesn't exist. The main groups of polymers which are using in medicine aren't deprived in this regard a set of shortcomings. Thus, need of search of such way of protection of biomedical materials which would keep their positive properties for a long time is obvious, and at the same time would provide their sterility and biological inertness, определяемою with their functional purpose.

Biological compatibility of carbon with sphybridization of atoms is a priori predicted by Rouf R. et Williams D. in 1975 [1]. Besides, the oriented layers of sp-carbon are capable to change lattice parameter, i.e. are labile, pass ions and molecules of liquids, working as the molecular filter. The last property is explained by van der Waals' interaction of chains among themselves that does possible their drawing apart at interaction with molecules and ions [2-3]. Other major property of coatings based on linear acetylenic carbon (LAC) is uniqueness of their mechanical properties: adhesions; durability and elasticity [4-6].

Actively being applied in medicine polyurethane is among polymers. One of scopes of polyurethane is their use at production of the artificial ventricles of heart $(\mathrm{AVH})$ for left ventricle assists systems (LVAS) and artificial heart (AH) devices.

Primarily, the choice of polyurethane is due to its physical and mechanical properties: elasticity or rigidity, mechanical strength, transparency. Besides that, the following factors are taken into account: manufacturability of production and low labor intensity of processing, the possibility of sterilization of the final product made from the selected material.

However purely technical polyurethane - biologically active material, and it can't be used for products of medical appointment. The polyurethane used in medicine, has own polymeric structure and contains high percent of the additives providing decrease in their toxicity and demanded mechanical properties. Therefore it is necessary to use such methods of preparation of a material which would keep demanded mechanical characteristics and provided biocompatible properties of a material.

One of solutions of this problem is modification of surface layer of the main material. For modification of surfaces of polymers, including AVH it is used or texturing of [7] surfaces, or depositing various on a chemical composition and the nature of coatings $[8,9]$. Thus, one of the perspective directions on creation of biomedical materials with high mechanical properties and biocompatible indicators is modifying of surfaces of polymers due to formation of single-layer, multilayered, simple or difficult chemical composition coatings.

In this work results of researches of physicomechanical and adhesive properties of the carbon coatings deposited on a surface of polyurethane for its further application as a material for production of AVH are described.

\section{Materials and Methods}

Carbon coating thickness $\sim 500 \AA$ Á, deposited on polyurethane VITUR PF TM-0333-95 by ion plasma deposition method. VITUR PF TM-0333-95 was selected as material, which have a positive toxicological certificate issued by FGBI "All-Russian Scientific and Research Organization for Medical Engineering" of Federal Service on sur-

* Corresponding author: blv vlsu@mail.ru 
veillance in healthcare" (Moscow, Russia). The basic physico-mechanical properties of these materials are shown in the table 1 .

Table 1. The basic physico-mechanical properties of VITUR PF TM-0333-95

\begin{tabular}{|c|c|c|c|c|}
\hline $\begin{array}{c}\text { Ultimate } \\
\text { tensile } \\
\text { strength, } \\
\text { MPa }\end{array}$ & $\begin{array}{c}\text { Elongation } \\
\text { at break, } \\
\%\end{array}$ & $\begin{array}{c}\text { Shore } \\
\text { hard- } \\
\text { ness, } \\
\text { method } \\
\text { A }\end{array}$ & $\begin{array}{c}\text { Mini- } \\
\text { mal } \\
\text { tear } \\
\text { re- } \\
\text { sis- } \\
\text { tance, } \\
\text { N/mm }\end{array}$ & $\begin{array}{c}\text { Stress at } \\
\mathbf{1 0 0} \% \\
\text { strain, } \\
\text { MPa }\end{array}$ \\
\hline 30 & & & 120 & 5 \\
\hline
\end{tabular}

The structure of deposited LAC film is shown in figure 1.

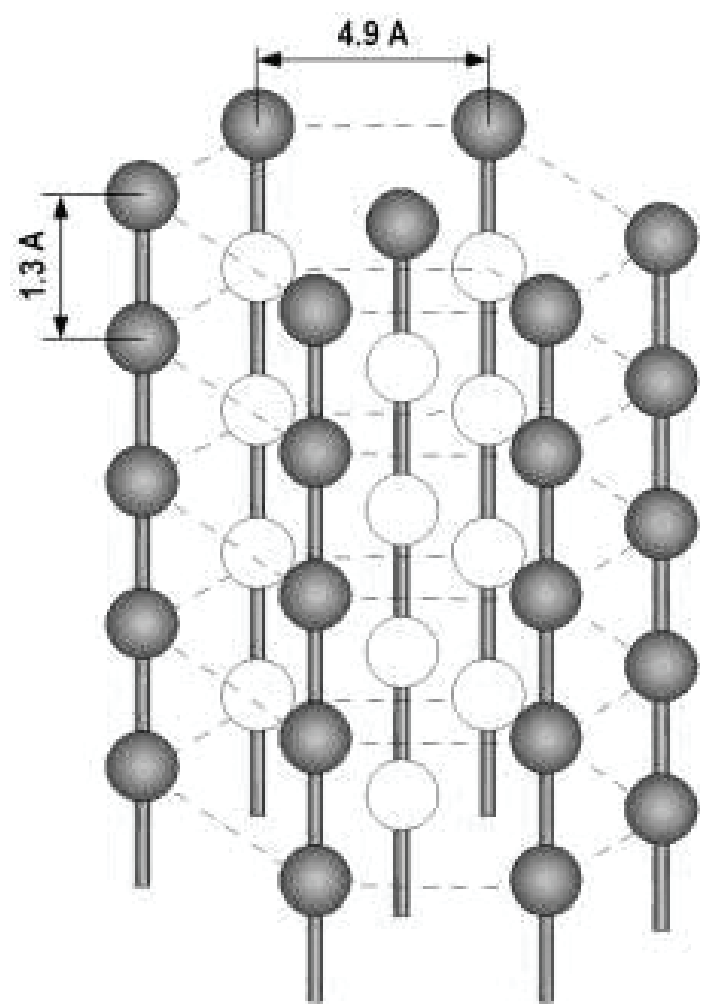

Fig. 1. The model image of deposited LAC film structure

The structural analysis and measurement of physicomechanical properties was carried out on a scanning electron microscope (SEM) "Quanta 200 3D", atomicforce microscope (AFM) "NTEGRA Aura", scanning nanohardness tester "Nanoskan-3D". The main difference of scanning nanohardness tester of the "Nanoskan" series from classical scanning probe microscopes (SPM) is application of a piezo-ceramic probe sensor with high bending stiffness of the cantilever. Using of the resonance oscillation mode allows exercising control of contact between probe and surface in two parameters: change of amplitude and oscillation of a probe. The resonant operating mode of a probe provides high stability of amplitude and frequency of oscillation and guarantees soft contact between probe and material surface during scanning process. On the basis of the scanning nanohardness tester "Nanoskan-3D" for measurements of mechanical properties of a surface the method of a measuring indentation according to recommendations of the international standard ISO 14577, and also a sklerometer method is realized. The sklerometer method has a several advantages than cave-in methods at measurement of hardness of films at a nanoscale [10]. Scratching with variable loading gives the chance to determine at the same time some parameters of a film within one measuring procedure: area of elastic interaction, threshold loading at which plastic deformation, conditions film peeling begins. Comparative researches of physico-mechanical characteristics of an initial surface of polyurethane and sample with the put covering it was made on the scanning nanohardness tester "NanoScan3D". The Berkovich tip of indenter was applied to mechanical tests.

\section{Results}

Micrographs of polyurethane surfaces received by means of SEM are presented in fig. 2. Application of this method of research allows assuming only that result of deposition on polymer surface of the thin film having noncontinuous which quantity decreases with increase in thickness of a coating is formed.

Obviously, that this technique of research of such coatings (films) is low-informative and demands application of other methods of structural researches, for example - scanning probe microscopy (SPM).

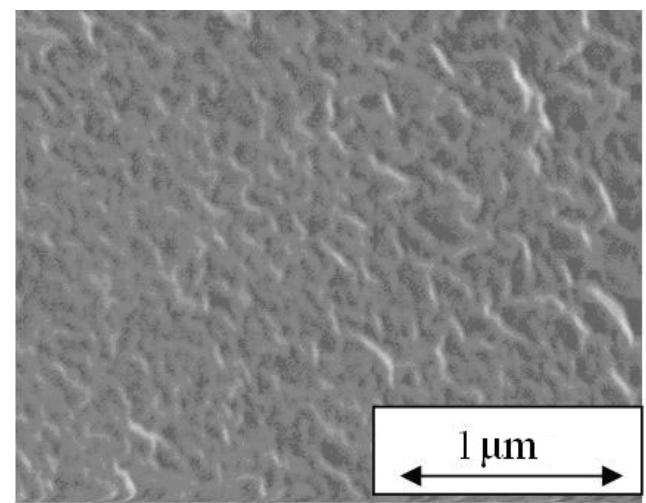

a)



b)

Fig. 2. Micrographs (SEM) of polyurethane surface: a) without film; b) with LAC deposited film

AFM-image of a surface samples with film and without coating are presented in fig. 3. The presented images 
have distinctions, confirming coatings about existence on a polyurethane surface. The flat and volume image of a sample with a carbon film is submitted in fig. of $3 \mathrm{c}$, d.
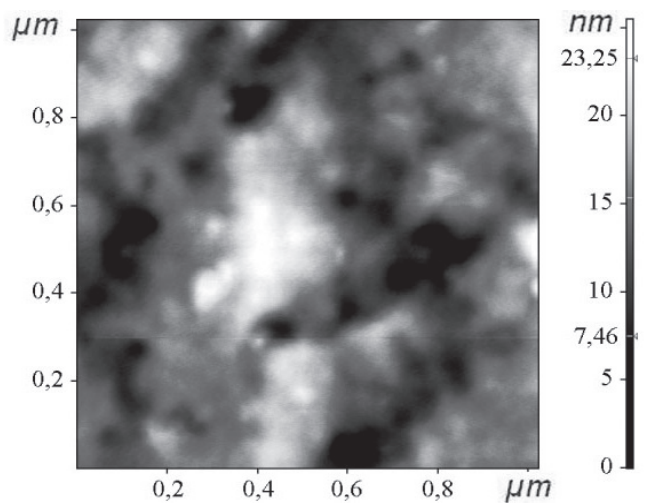

a)
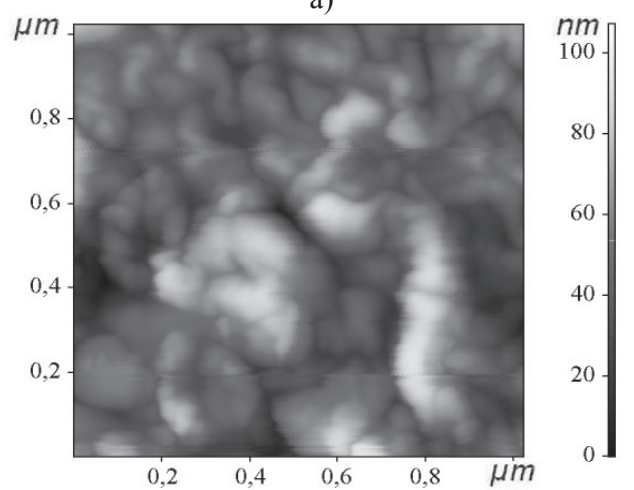

b)

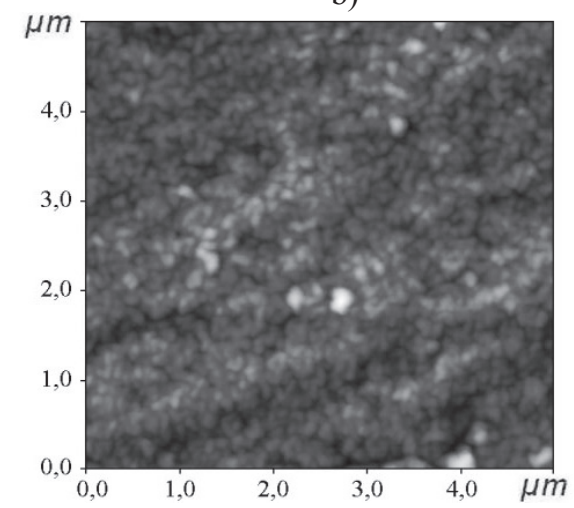

c)

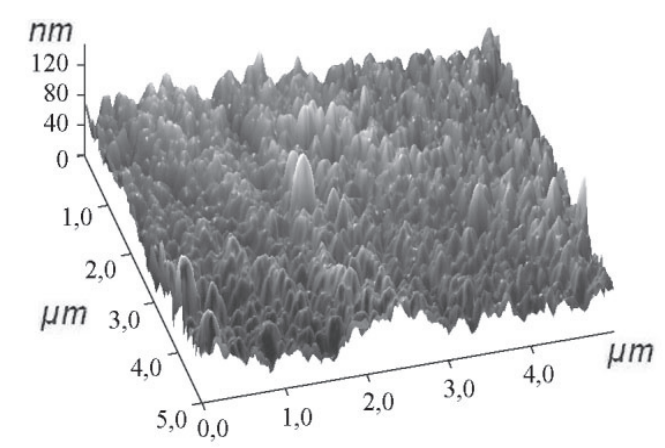

d)

Fig. 3. AFM-images of polyurethane surface: a) without film; b-d) with LAC deposited film

The analysis of the surface relief of sample allowed determining main parameters of microroughnesses of surface with the deposited coating: maximum roughness depth (Rmax) - $147.843 \mathrm{~nm}$; arithmetic average of the absolute values of the roughness profile $(\mathrm{Ra})-11.931$ $\mathrm{nm}$; average maximum height of the profile $(\mathrm{Rz})-$ 125.573 nanometers.

The method of a measuring indentation obtained data on values of hardness, the elasticity module, and coefficient of elastic restoration. Range of the maximum loadings at an indentation was from $100 \mu \mathrm{N}$ to $5 \mathrm{mN}$. Feature of studied materials is the high coefficient of restitution at the indentation, reaching $\sim 95 \%$. This effect is manifested in the fact that the load curve on the «loadindentation» chart almost coincides with the discharge curve (fig. 4).

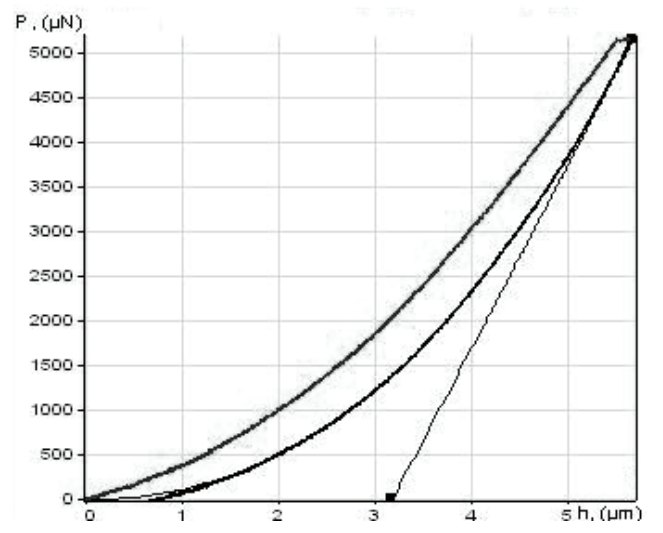

Fig. 4. Correlation between load $\mathrm{P}$ and depth of indentation $\mathrm{h}$ for coated polyurethane substrate

On the presented diagram of dependence of hardness from depth of indentation of an indenter (fig. 5 a) values of hardness of samples and without it practically coincide with a coating within casual variability of data this results from the fact that the loading curve almost coincides from curve unloading.

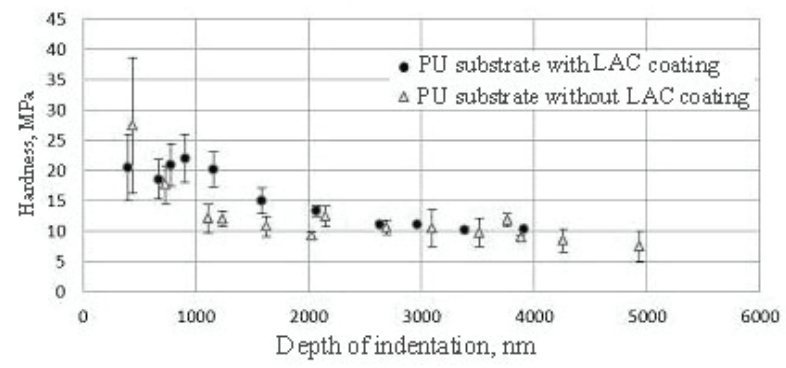

a)

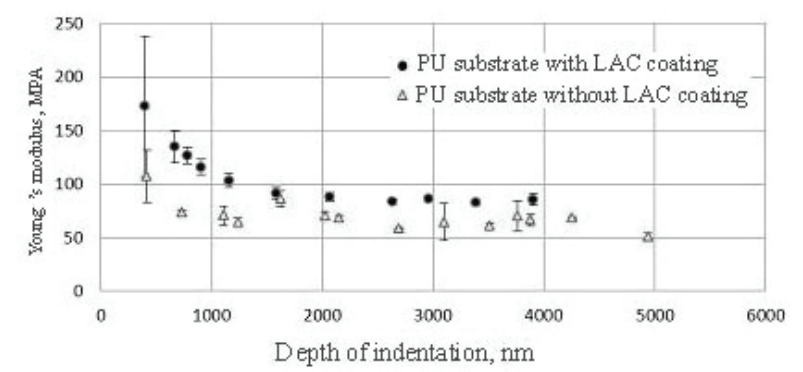

b)

Fig. 5. Mechanical properties of research samples (the load range: 0,1 to $5 \mathrm{mN}$ ): a) hardness; b) Young's modulus 
At the same time, the values of the module of elasticity calculated on the same experimental data (fig. of $5 \mathrm{~b}$ ), show considerable (1.5-2 times) module excess on a surface with a coating.

The presented data (fig. 6) show that essential distinction of mechanical properties is observed with a depth of indentation less than $1 \mu \mathrm{m}$. This size is connected with a ratio of depth of an indentation and film thickness: with a depth of indentation of the indenter, a film comparable to thickness measured value generally is defined by properties of a substrate. At the same time, the measured module of elasticity of a surface with a film remains to higher, than at an initial material at depths of indentation of the indenter, many times exceeding film thickness. It testifies that the coating keeps elastic properties and doesn't destroy at large relative deformations.

The sklerometer method was applied to research of durability and adhesive properties of coating with variable loading. Scratches about $75 \mu \mathrm{m}$ length were put on surfaces of samples, load changed from 0 to $5 \mathrm{mN}$. The scratch test of polyurethane without coating leads to formation of scratches with indistinctly outlined edges up to $500 \mathrm{~nm}$ in depth. Similar experiment on a sample with a covering (fig. 6) doesn't lead to essential deformation of a surface, except for flows at the end of scratch with the maximum loading $5 \mathrm{mN}$, connected, apparently, with partial transfer of a material on a surface. Thus film flaking from a substrate that speaks about good adhesive properties of a covering isn't observed.



Fig. 6. AFM-image of surface sample with LAC after variable load scratch test: 0 to $1 \mathrm{mN}$ (left) and 0 to $5 \mathrm{mN}$ (right)

\section{Conclusions}

Results of the conducted researches of a relief and physico-mechanical properties of coverings on the basis of LAC deposited on polyurethane, the SPM methods, a nanoindentation and sklerometer method show that deposited coatings reduce porosity of a surface, increase its durability and wear resistance, increase elasticity and coefficient of elastic restoration at deformation. The coating has high degree of adhesion to a substrate and doesn't exfoliate at mechanical influence. It is shown that the SPM methods, a measuring indentation and sklerom- eter method can be used for quality control of carbon coatings on products from polyurethane.

\section{References}

1. D.Williams, R. Rouf, Implants in surgery (in Russian), Medicine, Moscow, (1978).

2. A. F. Aleksandrov, M.B. Guseva, Yu. V. Korneeva, et al., The results and perspectives of biocompatible forms linear acetylenic carbon application in medicine (in Russian), Integral., 5 (61) 27-31, (2011).

3. V.G. Babaev, N.D. Novikov, M.B. Guseva, GCKcarbon - unique nanophase of carbon (in Russian), Nanotechnologies: development, application., 153 68 (2010).

4. D.A. Malinin, Yu. G. Aleksandov, N.D. Novikov, Use linear acetylenic carbon coating for the purpose of protection of polymeric artificial limbs of an eardrum against destruction and immunological reactions, Nonmaterial, Nanotechnologies - medicine., 10, 64-69 (2007).

5. N.V. Dobrova, Research of vascular artificial limbs from carbon contain fiber Vitlan. Topical issues of the organization, prevention and surgical treatment of diseases of the main vessels (in Russian), Medicine, Moscow, (1991).

6. D.A. Malinin, Yu. G. Aleksandov, A.M Al-Naser, Way of preservation of the implants applied in myringoplasty, Modern problems of physiology and hearing pathology 1, 103 - 104 (2011).

7. P. B. Kwant, Implantable electromechanical displacement blood pumps: systematic design and validation methods, (2007) Available at: (http://darwin.bth.rwthaachen.de/opus3/volltexte/20 08/2380/pdf/Kwant_Paul.pdf).

8. J. Sarna, R. Kustosz, R. Major, J. Lackner, B. Major, Polish Artificial Heart - new coatings, technology, diagnostics, Bull. Pol. Ac.: Tech. 58 (2), 329-335 (2010).

9. J. Lavee, Y. Paz, Mechanical Alternatives to the Human Heart: Paracorporeal Assist Systems, IMAJ, 4, 125 - 130, (2002).

10. A.S. Eseinov, K.V. Gogolinsky, V.N. Reshetov, Measurement of mechanical properties of superfirm diamondlike carbon coverings (in Russian), News of higher education institutions. Chemistry and chemical technology, 7 51-54 (2011). 